\title{
Synthesis of $\mathrm{SiO}_{2} / \mathrm{SnO}_{2}$ nanofibers using TEMPO- oxidized cellulose nanofibers as templates
}

\author{
Shunsuke Gunji*, Yasuhiko Shimotsuma*, Tetsuya Fujimoto and Kiyotaka Miura \\ Department of Material Chemistry, Graduate School of Engineering, Kyoto University, Kyoto, Japan
}

\begin{abstract}
$\mathrm{SiO}_{2} / \mathrm{SnO}_{2}$ nanofibers were synthesized using templates of TEMPO-oxidized cellulose nanofibers $(\mathrm{TOCN})$. $\mathrm{SiO}_{2}$ and $\mathrm{SnO}_{2}$ were sequentially deposited onto the TOCN via sol-gel reactions. Acetylacetone (acac) and $\mathrm{NH}_{3}$ were used to stabilize the precursor of $\mathrm{SnO}_{2}$ through the formation of tin acetylacetonate. After the combustion of TOCN templates, $\mathrm{SiO}_{2} / \mathrm{SnO}_{2}$ nanofibers which were composed of amorphous $\mathrm{SiO}_{2}$ and rutile phase $\mathrm{SnO}$ nanocrystals were obtained. Especially with the acac/Sn molar ratio of 500 under the use of $\mathrm{NH}_{3}$, the $\mathrm{SiO}_{2} / \mathrm{SnO}_{2}$ nanofibers with the fine structure derived from TOCN templates were formed. They showed a very small diameter of around $8 \mathrm{~nm}$ and a high specific surface area of $322 \mathrm{~m}^{2} / \mathrm{g}$. The $\mathrm{SnO}_{2}$ crystallite size was kept to be $3.2 \mathrm{~nm}$ by suppressing the coarsening. We have also evaluated the gas-sensitivity to $1000 \mathrm{ppm}$ ethanol of the synthesized $\mathrm{SiO}_{2} / \mathrm{SnO}_{2}$ nanofibers. By adding acac under the use of $\mathrm{NH}_{3}$ leading to the suppression of the growth of the $\mathrm{SnO}_{2}$ crystallite size, this sensitivity was enhanced 10 times larger.
\end{abstract}

\section{Introduction}

Nanofibers have remarkable properties of high mechanical strength, high specific surface area, hydrodynamic characteristics, and electrical conductivities [1-4]. Especially, semiconducting metal oxide nanofibers, such as $\mathrm{SnO}_{2}$ nanofibers, are expected to be one of key materials for gas sensing devices due to their unique electrical features [5]. Although nanofibers are conventionally produced by several ways, such as electrospinning, it is difficult to synthesize nanofibers with a diameter of ten nanometers or less [6-8]. According to the various reports on the fabricating inorganic nanofibers using the templates of cellulose nanofibers [9-12], the advantages of these procedures are basically to obtain inorganic nanofibers maintaining the fine structure corresponding to the original cellulose. More recently, we developed the method to synthesize very thin $\mathrm{SiO}_{2} / \mathrm{TiO}_{2}$ core-shell nanofibers with a diameter below ten nanometers [13] using the special cellulose nanofibers which are called (2,2,6,6-tetramethyl-piperidin-1-yl)oxyl (TEMPO) oxidized cellulose nanofibers (TOCN) [14]. In this synthesis method, initially deposited $\mathrm{SiO}_{2}$ helps $\mathrm{TiO}_{2}$ to attach onto the cellulose nanofiber via a covalent bonding. Here, we report the synthesis of $\mathrm{SiO}_{2} / \mathrm{SnO}_{2}$ composite nanofibers by using TOCN. In the synthesis procedure, $\mathrm{SiO}_{2}$ and $\mathrm{SnO}_{2}$ were sequentially deposited onto the surface of TOCN. And then, the templates TOCN were combusted to obtain $\mathrm{SiO}_{2} / \mathrm{SnO}_{2}$ nanofibers. Firstly, the deposition of $\mathrm{SiO}_{2}$ was performed via the series treatment of 3-aminopropyltrimethoxysilane (APTMS) and tetramethoxysilane (TMOS). Subsequently, $\mathrm{SnO}_{2}$ was deposited using tin (IV) tetraisopropoxide with acac as stabilizing agent $[15,16]$. It is well-known that the smaller crystallite size of $\mathrm{SnO}_{2}$ enhances its gas sensitivity [17]. In order to obtain the $\mathrm{SiO}_{2} / \mathrm{SnO}_{2}$ nanofibers with the enhanced sensitivity, the optimization of the acac/Sn molar ratio for the suppression of $\mathrm{SnO}_{2}$ crystallites size was investigated.

\section{Materials and methods}

\section{Preparation of TEMPO-oxidized cellulose nanofibers (TOCN)}

TOCN were prepared by the conventional method [18]. $4.00 \mathrm{~g}$ of fibrous cellulose (KY-100G, Daicel Fine Chem) was suspended in 400 $\mathrm{mL}$ of distilled water. $400 \mathrm{mg}$ of $\mathrm{NaBr}$ (Kishida Chemicals), $64.0 \mathrm{mg}$ of (2,2,6,6-tetramethylpiperidin-1-yl)oxyl (TEMPO, Sigma-Aldrich), and $12.4 \mathrm{~mL}$ of $\mathrm{NaClO}$ solution (Wako Pure Chemicals), were added and stirred for 2.5 hours at room temperature maintaing $\mathrm{pH}$ value of 10 . The obtained TOCN were repeatedly washed with distilled water and stored as an aqueous dispersion for further experiments.

\section{$\mathrm{SiO}_{2}$ deposition on TOCN}

The series treatments of two types of silicon alkoxide were used [13]. Firstly, $0.98 \mathrm{~mL}$ of 3-aminopropyltrimethoxysilane (APTMS, Sigma-Aldrich) was added to $100 \mathrm{~mL}$ of $1.0 \mathrm{wt} \%$ aqueous suspension of TOCN and stirred for $45 \mathrm{~min}$ at room temperature. After the stirring, the TOCN treated with APTMS were repeatedly washed with distilled water using centrifugation and were prepared to be $1.0 \mathrm{wt} \%$ aqueous

Correspondence to: Shunsuke Gunji, Master of Engineering, Ph.D. Student, Department of Material Chemistry, Graduate School of Engineering, Kyoto University, Kyoto 615-8510, Japan, Tel: +81-75-383-2463, Fax: +81-75-383-2461

Yasuhiko Shimotsuma. Ph.D. in Engineering, Associate Professor, Department of Material Chemistry, Graduate School of Engineering, Kyoto University, Kyoto 615-8510, Japan; Tel: +81-75-383-2459, Fax: +81-75-383-2461

Key words: nanofibers, sol-gel, $\mathrm{SiO}_{2}, \mathrm{SnO}_{2}$, cellulose nanofibers, gas sensor

Received: January 08, 2017; Accepted: January 23, 2017; Published: January 26, 2017 
suspension. Subsequently, $0.10 \mathrm{~mL}$ of tetramethoxysilane (TMOS, Sigma-Aldrich) was added to the suspension and stirred for $45 \mathrm{~min}$ at room temperature. The TOCN sequentially treated with APTMS and TMOS (in the following, $\mathrm{TOCN} / \mathrm{SiO}_{2}$ ) were repeatedly washed with distilled water. After that, the solvent was substituted with ethanol (Kishida Chemicals).

\section{Synthesis of $\mathrm{SiO}_{2} / \mathrm{SnO}_{2}$ nanofibers}

To deposit $\mathrm{SnO}_{2}$ onto the $\mathrm{TOCN} / \mathrm{SiO}_{2}$ surface, the hydrolysis and condensation reactions of tin alkoxide were employed. Certain amount of acetylacetone (acac, Kishida Chemicals), $3.06 \mathrm{~mL}$ of $28 \%$ $\mathrm{NH}_{3}$ aqueous solution (Kishida Chemicals) were added to ethanol dispersion containing $0.128 \mathrm{~g}$ of $\mathrm{TOCN} / \mathrm{SiO}_{2}$. After the further dilution with ethanol and addition of $0.928 \mathrm{~mL}$ of $10 \mathrm{w} / \mathrm{v} \%$ tin (IV) isopropoxide in isopropanol (Alfa Aesar), the mixture was stirred for $12 \mathrm{~h}$ at room temperature under an argon atmosphere. In the exceptional cases, distilled water was used instead of $\mathrm{NH}_{3}$ aqueous solution with maintaining the total amount of water. The amount of ethanol for the dilution was modified to make the total weight of the mixture $128 \mathrm{~g}$. Acac/Sn molar ratios were changed from 0 to 1000 . After washing repeatedly by isopropanol (Kishida Chemicals) using centrifugation at $4000 \mathrm{rpm}, \mathrm{TOCN} / \mathrm{SiO}_{2}$ covered with $\mathrm{SnO}_{2}$ were dried with a super critical dryer (SCRD 4, Rexxam) using $\mathrm{CO}_{2}$. $\mathrm{SiO}_{2} / \mathrm{SnO}_{2}$ nanofibers were obtained after the calcination of the dried sample at $500^{\circ} \mathrm{C}$ for $4 \mathrm{~h}$ in air via the combustion of the templates TOCN.

\section{Characterization}

Measurements of X-Ray diffraction (XRD) patterns were carried out by an X-Ray diffractometer (RINT-2500HFK, Rigaku). The crystallite size of $\mathrm{SnO}_{2}$ was calculated by Scherrer's equation with rutile $\mathrm{SnO}_{2}$ (101) peak. Observations of microscopic structures were conducted by a field-emission scanning electron microscope (FESEM; JSM-6700F, JEOL) and a transmission electron microscope (TEM; JEM-2200FS, JEOL). FT-IR spectra were measured by an FTIR spectrometer equipped with an ATR accessory (Spectrum Two, Perkin Elmer). Specific surface areas were determined by using an $\mathrm{N}_{2}$ adsorption-desorption apparatus (Tristar 3000, Shimadzu) after degassing at $150^{\circ} \mathrm{C}$.

\section{Evaluation of gas sensitivity}

The gas sensitivity of the synthesized $\mathrm{SiO}_{2} / \mathrm{SnO}_{2}$ nanofibers was evaluated by monitoring changes of an electrical resistance of the nanofibers during repeated exposure to the analyte gas containing ethanol. $\mathrm{SiO}_{2} / \mathrm{SnO}_{2}$ nanofibers were formed to be a sheet with a size and a thickness of about $8 \mathrm{~mm} \times 13 \mathrm{~mm}$ and $1 \mathrm{~mm}$, respectively. The gold electrode was deposited on the sheet by sputtering. The nanofibers sheet was placed on a ceramic heater inside a silica glass tube and the measurements were conducted at $400^{\circ} \mathrm{C}$. The analyte gas containing $1000 \mathrm{ppm}$ ethanol with the flow rate of $300 \mathrm{sccm}$ was prepared by using the mass flow controllers (SEC-E40, Horiba Stec).

\section{Results and discussion}

Figure 1 shows the synthesis procedure of the $\mathrm{SiO}_{2} / \mathrm{SnO}_{2}$ nanofibers schematically.

Figure 2 shows XRD patterns of $\mathrm{SiO}_{2}$ and $\mathrm{SiO}_{2} / \mathrm{SnO}_{2}$ nanofibers synthesized with various acac/Sn molar ratios. All $\mathrm{SiO}_{2} / \mathrm{SnO}_{2}$ nanofibers had rutile phase $\mathrm{SnO}_{2}$ (JCPDS card no. 41-1445), in contrast to no crystalline peaks in $\mathrm{SiO}_{2}$. Inset denotes the relationship between acac/Sn ratios and crystallite sizes. It should be noted that $\mathrm{SiO}_{2} / \mathrm{SnO}_{2}$
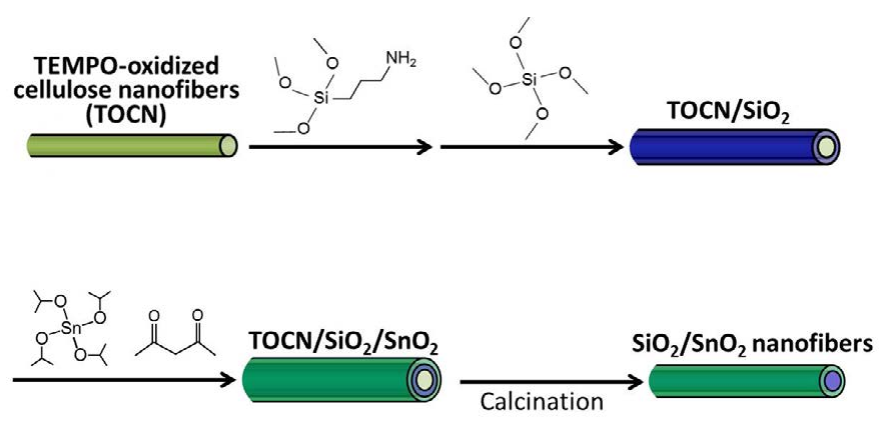

Figure 1. Schematic procedure for synthesis of $\mathrm{SiO}_{2} / \mathrm{SnO}_{2}$ nanofibers.

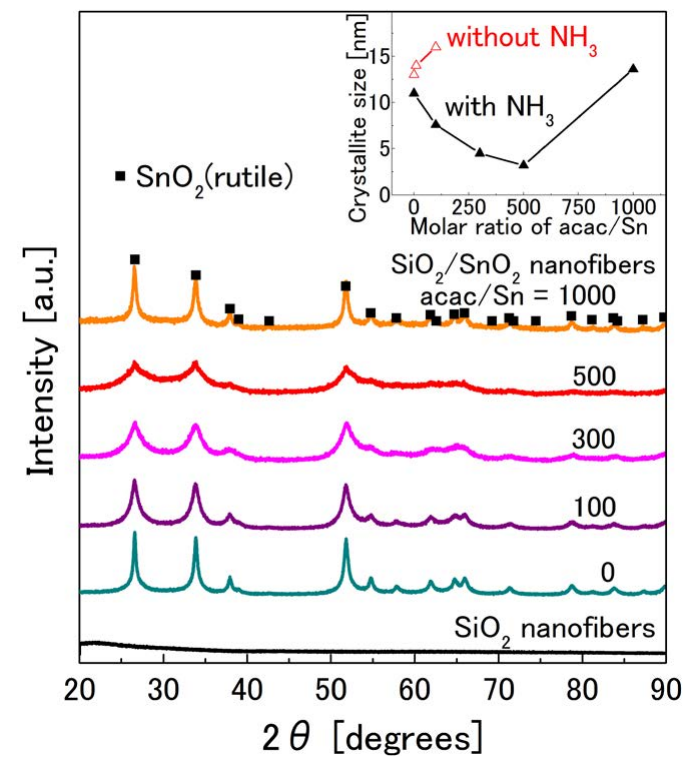

Figure 2. XRD patterns of $\mathrm{SiO}_{2}$ and $\mathrm{SiO}_{2} / \mathrm{SnO}_{2}$ nanofibers synthesized with various acac/ $\mathrm{Sn}$ molar ratios. Inset plot indicate relationship between acac/Sn molar ratios and crystallite size of $\mathrm{SnO}_{2}$. Red-colored plots indicate results of $\mathrm{SiO}_{2} / \mathrm{SnO}_{2}$ nanofibers without use of $\mathrm{NH}_{3}$ as exceptional cases.

nanofibers obtained by the acac/Sn ratio of 500 showed the smallest crystallite size of $3.2 \mathrm{~nm}$. In the exceptional cases without $\mathrm{NH}_{3}$, the crystallite sizes remained still high. Therefore, in the following, we focused on the results with the use of $\mathrm{NH}_{3}$.

Figure 3 shows FE-SEM images of TOCN, $\mathrm{SiO}_{2}$ nanofibers, and $\mathrm{SiO}_{2} / \mathrm{SnO}_{2}$ nanofibers with various acac/Sn ratios. The $\mathrm{SiO}_{2} / \mathrm{SnO}_{2}$ nanofibers with the acac/Sn ratio of 500 maintained the fine structure derived from TOCN, however, the others possessed considerably coarse grains. These coarsening are corresponding to the large crystallite sizes in the inset of Figure 2. From these results, it was revealed that the use of $\mathrm{NH}_{3}$ and appropriate amount of acac can suppress the undesirable large grains. The generation of such coarse grains would be interpreted as follows; since a homogeneous nucleation via a self-condensation of tin isopropoxide occurred, these nuclei grew and then attached onto the surface of the nanofibers. Here the effect of acac can be explained by the formation of tin acetylacetonate. Such tin acetylacetonate, which is less reactive than tin alkoxide [15,16], suppressed self-condensation and finally caused the selective deposition on the nanofibers surface. In this study, since the formation of acetylacetonate occurred at the same time as the hydrolysis of tin isopropoxide, much more amount of acac compared to the stoichiometric acac/Sn molar ratio, which is up to 2, was required. It is assumed that the basicity of $\mathrm{NH}_{3}$ helped the formation of tin acetylacetonate through the deprotonation of acac 
[19]. On the other hand, it is expected that $\mathrm{NH}_{3}$ also acted as base for the dissolution of small nuclei derived from the self-condensation. Since acac is weak acid, the too much amount as acac/Sn ratio of 1000 caused the insufficiency of basicity for the dissolution of nuclei derived from the self-condensation, leading to the coarsening of $\mathrm{SnO}_{2}$ crystallites. It should be emphasized that a smaller crystallite size is desirable for a more sensitive gas sensor [17]. By TEM observation (Figure 3F-H), $\mathrm{SiO}_{2} / \mathrm{SnO}_{2}$ nanofibers with the acac/Sn ratio of 500 had the diameter of around $8 \mathrm{~nm}$. They were covered with rutile $\mathrm{SnO}_{2}$ nanocrystals (Figure $3 \mathrm{G}, \mathrm{H})$. It can be interpreted that $\mathrm{SiO}_{2} / \mathrm{SnO}_{2}$ nanofibers have the core/ shell structure reflecting the sequential deposition of $\mathrm{SiO}_{2}$ and $\mathrm{SnO}_{2}$ [13].

Furthermore, they exhibited an enormously high specific surface area of $322 \mathrm{~m}^{2} / \mathrm{g}$ (Table 1). The IR spectrum of $\mathrm{SiO}_{2} / \mathrm{SnO}_{2}$ nanofibers with the acac/Sn ratio of 500 was compared to that of the $\mathrm{SiO}_{2}$ nanofibers (Figure 4). Typical amorphous $\mathrm{SiO}_{2}$ peaks, such as $\mathrm{Si}-\mathrm{O}-\mathrm{Si}$ asymmetric stretching modes peaks around $1250 \mathrm{~cm}^{-1}$ and $1080 \mathrm{~cm}^{-1}$ [20], were observed in both samples. In the case of the $\mathrm{SiO}_{2} / \mathrm{SnO}_{2}$ nanofibers, the peak at around $970 \mathrm{~cm}^{-1}$ and the broad peak between 700 and $400 \mathrm{~cm}^{-1}$ are assigned to $\mathrm{Si}-\mathrm{O}-\mathrm{Sn}$ stretching mode and typical $\mathrm{SnO}_{2}$ absorption, respectively $[21,22]$. Due to the presence of Si-O-Sn peak, this result can be interpreted by the existence of the covalent bonding between $\mathrm{SnO}_{2}$ and $\mathrm{SiO}_{2}$.

Figure 5 shows the resistance changes of the $\mathrm{SiO}_{2} / \mathrm{SnO}_{2}$ nanofibers with the different synthesis conditions under the cyclic exposure to the analyte gas containing $1000 \mathrm{ppm}$ ethanol. The gas sensitivity is defined as the ratio of the resistance before and after the exposure to an analyte gas [17]. The relationships between the crystallite sizes and sensitivities for the synthesized $\mathrm{SiO}_{2} / \mathrm{SnO}_{2}$ nanofibers were shown in Table 1. The $\mathrm{SiO}_{2} / \mathrm{SnO}_{2}$ nanofibers with the acac/Sn ratio of 500 exhibited the simply high sensitivity value of 228 which is about 10 times as high as that with the acac/Sn of 0 . It can be interpreted in terms of their smaller crystallite size [17].

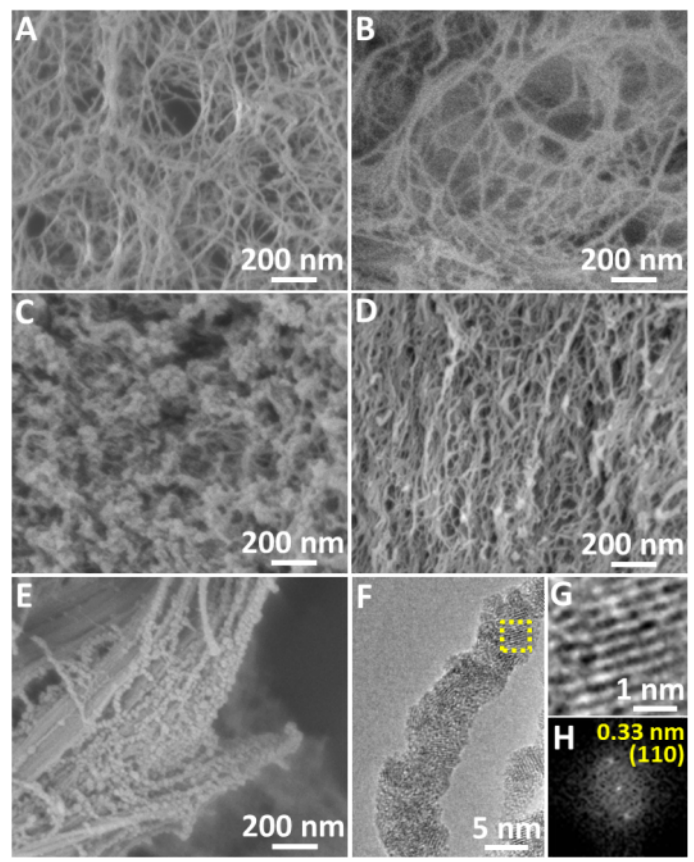

Figure 3. FE-SEM images of (A) TOCN, (B) $\mathrm{SiO}_{2}$ nanofibers, (C)-(E) $\mathrm{SiO}_{2} / \mathrm{SnO}_{2}$ nanofibers synthesized with acac/Sn molar ratio of $0,500,1000$, respectively. TEM image of (F) $\mathrm{SiO}_{2}$ $\mathrm{SnO}_{2}$ nanofibers synthesized with acac/Sn molar ratio of 500, (G) high magnified image of selected area in (F). FFT image of (F) is shown in (H).

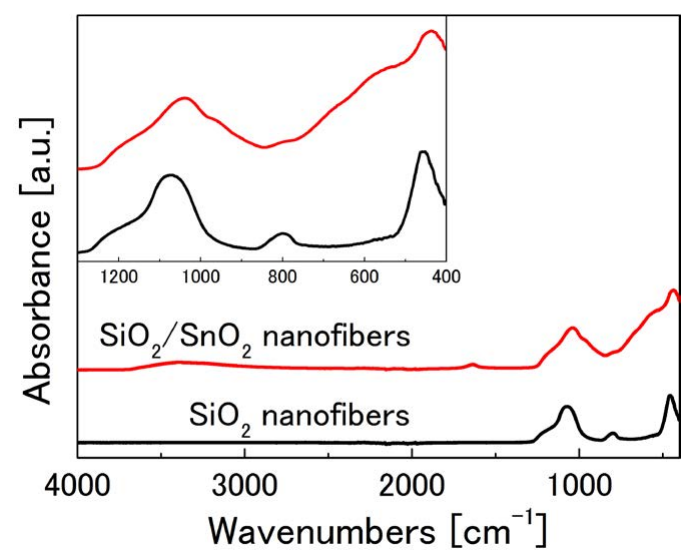

Figure 4. FT-IR spectra of $\mathrm{SiO}_{2}$ nanofibers and $\mathrm{SiO}_{2} / \mathrm{SnO}_{2}$ nanofibers synthesized with acac/Sn molar ratio of 500 .

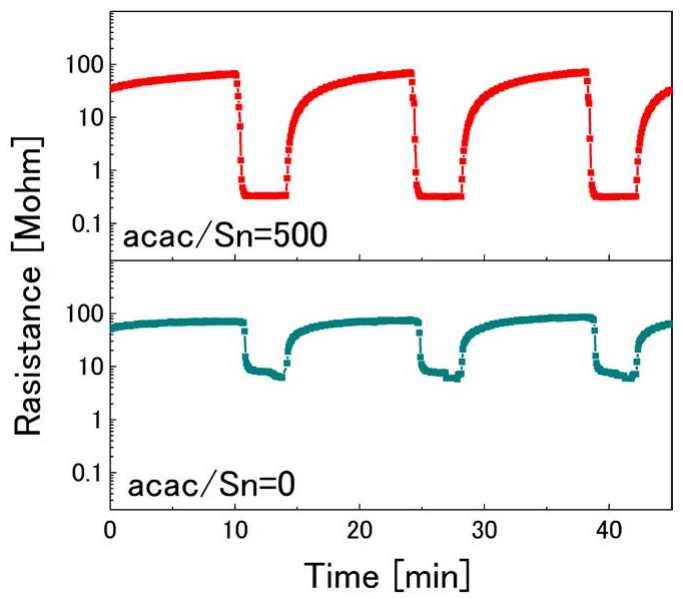

Figure 5. Repetitive responses to $1000 \mathrm{ppm}$ ethanol gas at $400^{\circ} \mathrm{C}$.

\section{Conclusion}

We successfully synthesized $\mathrm{SiO}_{2} / \mathrm{SnO}_{2}$ nanofibers using TEMPOoxidized cellulose nanofibers (TOCN) as templates. To obtain $\mathrm{SiO}_{2}$ / $\mathrm{SnO}_{2}$ nanofibers, the templates of TOCN were combusted after the sequential deposition of $\mathrm{SiO}_{2}$ and $\mathrm{SnO}_{2}$ onto the surface of TOCN. $\mathrm{SiO}_{2} / \mathrm{SnO}_{2}$ were composed of amorphous $\mathrm{SiO}_{2}$ and rutile phase $\mathrm{SnO}_{2}$ nanocrystals. The detailed crystalline and microscopic structures were investigated in relation to the deposition condition of $\mathrm{SnO}_{2}$. The key factor was the molar ratio of acac/Sn and the presence of $\mathrm{NH}_{3}$. The optimal molar ratio of acac/Sn was 500 under the use of $\mathrm{NH}_{3}$. Since such optimized $\mathrm{SiO}_{2} / \mathrm{SnO}_{2}$ nanofibers keep the fine structure derived from TOCN, it can be expected that the crystallite size is controllable. Indeed, the synthesized nanofibers had a very thin diameter of around $8 \mathrm{~nm}$ and the smallest crystallite size of rutile $\mathrm{SnO}_{2}$ of $3.2 \mathrm{~nm}$. We have also demonstrated that these nanofibers exhibited the high gas sensitivity of 228 to $1000 \mathrm{ppm}$ ethanol, which is derived from the small crystallite size of $\mathrm{SnO}_{2}$. The synthesized $\mathrm{SiO}_{2} / \mathrm{SnO}_{2}$ nanofibers are also expected to exhibit high gas sensitivity to other volatile organic compounds (VOC). More detailed investigations are required.

\section{Acknowledgements}

This work was partially supported by JSPS KAKENHI Grant Number 16K13929, The Thermal \& Electric Energy Technology Foundation, Tokuyama Science Foundation, Cross-Ministerial 
Strategic Innovation Promotion (SIP) Program, and Nanotechnology Platform Program of MEXT, JAPAN.

\section{References}

1. Chen F, Peng X, Li T, Chen S, Wu XF, Reneker HR, Houl H (2008) Mechanical characterization of single high-strength electrospun polyimide nanofibers. Journal of Physics D: Applied Physics 41: 025308.

2. Thavasi V, Singh G, Ramakrishna S (2008) Electrospun nanofibers in energy and environmental applications. Energy \& Environmental Science 1: 205.

3. Aronggaowa B, Toda Y, Ito N, Shikinaka K, Shimomura T (2013) Transparent conductive films fabricated from polythiophene nanofibers composited with conventional polymers. Polymers 5: 1325.

4. Shen S, Henry A, Tong J, Zheng R, Chen G (2010) Polyethylene nanofibres with very high thermal conductivities. Nat Nanotechnol 5: 251-255. [crossref]

5. Arafat MM, Dinan B, Akbar SA, Haseeb AS (2012) Gas sensors based on one dimensional nanostructured metal-oxides: a review. Sensors (Basel) 12: 7207-7258. [crossref]

6. Kim I-D, Rothschild A (2011) Nanostructured metal oxide gas sensors prepared by electrospinning. Polymers for Advanced Technologies 22: 318 .

7. Li D, Xia Y (2004) Electrospinning of nanofibers: reinventing the wheel? Advanced Materials 16: 1151.

8. Holmström SC, King PJS, Ryadnov MG, Butler MF, Mann S, Woolfson DN (2008) Templating silica nanostructures on rationally designed self-assembled peptide fibers. Langmuir 24: 11778 .

9. Gu Y, Huang J (2013) Precise size control over ultrafine rutile titania nanocrystallites in hierarchical nanotubular silica/titania hybrids with efficient photocatalytic activity. Chemistry - A European Journal 19: 10971.

10. Zhang Y, Liu X, Huang J (2011) Hierarchical mesoporous silica nanotubes derived from natural cellulose substance. ACS Applied Materials \& Interfaces 3: 3272.

11. Korhonen JT, Hiekkataipale P, Malm J, Karppinen M, Ikkala O, et al. (2011) Inorganic hollow nanotube aerogels by atomic layer deposition onto native nanocellulose templates. ACS Nano 5: 1967-1974. [crossref]

12. Huang J, Matsunaga N, Shimanoe K, Yamazoe N, Kunitake T (2005) Nanotubular $\mathrm{SnO} 2$ templated by cellulose fibers: synthesis and gas sensing. Chemistry of Materials 17: 3513 .

13. Gunji S, Shimotsuma Y, Miura K (2016) Synthesis and photocatalytic properties of $\mathrm{SiO} 2 / \mathrm{TiO} 2$ nanofibers using templates of TEMPO-oxidized cellulose nanofibers. Journal of Sol-Gel Science and Technology 79: 151.

14. Isogai A, Saito T, Fukuzumi H (2011) TEMPO-oxidized cellulose nanofibers. Nanoscale 3: 71-85. [crossref]

15. Hampden-Smith MJ, Wark TA, Brinker CJ (1992) The solid state and solution structures of tin(IV) alkoxide compounds and their use as precursors to form tin oxide ceramics via sol-gel-type hydrolysis and condensation. Coordination Chemistry Reviews 112: 81 .

16. Briois V, Belin S, Chalaça MZ, Santos RHA, Santilli CV, Pulcinelli S (2004) Solidstate and solution structural study of acetylacetone-modified Tin(IV) chloride used as a precursor of $\mathrm{SnO} 2$ nanoparticles prepared by a sol-gel route. Chemistry of Materials 16: 3885 .

17. Xu C, Tamaki H, Miura N, Yamazoe N (1991) Grain size effects on gas sensitivity of porous SnO2-based elements. Sensors and Actuators B: Chemical 3: 147.

18. Saito T, Kimura S Nishiyama Y, Isogai A (2007) Cellulose nanofibers prepared by TEMPO-mediated oxidation of native cellulose. Biomacromolecules 8: 2485.

19. Seco M (1989) Acetylacetone: a versatile ligand. Journal of Chemical Education 66: 779 .

20. Wang J, Zou B, El-Sayed MA, (1999) Comparison between the polarized Fouriertransform infrared spectra of aged porous silicon and amorphous silicon dioxide films on Si (100) surface. Journal of Molecular Structure 508: 87.

21. Shah P, Ramaswamy AV, Lazar K, Ramaswamy V (2004) Synthesis and characterization of tin oxide-modified mesoporous SBA-15 molecular sieves and catalytic activity in trans-esterification reaction. Applied Catalysis A: General 273: 239.

22. Amalric-Popescu D, Bozon-Verduraz F (2001) Infrared studies on $\mathrm{SnO}_{2}$ and $\mathrm{Pd} / \mathrm{SnO}_{2}$ Catalysis Today 70: 139.

Copyright: (C2017 Gunji S. This is an open-access article distributed under the terms of the Creative Commons Attribution License, which permits unrestricted use, distribution, and reproduction in any medium, provided the original author and source are credited. 